\title{
In vivo changes in oocyte germinal vesicle related to follicular quality and size at mid-follicular phase during stimulated cycles in the Cynomolgus monkey
}

\author{
B. Lefèvre, A. Gougeon, F. Nomé and J. Testart
}

INSERM, unité 187 physiologie et psychologie de la reproduction humaine, 32 rue des Carnets, 92140, Clamart, France

(3rd Franco-Czechoslovak Meeting, INRA, Jouy-en-Josas, 13-14 December 1988)

\begin{abstract}
Summary - Histological examination of gonadotrophin stimulated Macaca fascicularis ovaries removed at mid-follicular phase showed that germinal vesicles (GV) could exhibit different configurations in follicles $>1000 \mu \mathrm{m}$ in diameter. We describe 3 types of nuclear organization called GV1 (dispersed and filamentous chromatin), GV2 (clumped and filamentous chromatin) and GV3 (perinucleolar chromatin condensation). Gonadotrophin stimulation and follicular atresia induced modifications in GV chromatin dispersion. Such modifications were of a higher degree in the case of atresia which could even induce in vivo germinal vesicle breakdown (GVBD). Our findings were as follows. The frequency of GV1 oocytes was always low, but was higher in healthy than in atretic follicles, whereas GV3 oocytes were more frequent in atretic compared to healthy follicles; the oocytes which resumed meiosis in vitro were most probably those which were at the GV3 stage at the time of recovery; GV nuclear changes were related to follicle size and quality, but not to oocyte size. The mean follicular size increased from GV1 to GV3 oocyte stages whatever the follicle quality; the nucleus was often observed in a peripheral position even in GV1 oocytes; zona pellucida appearance was related to GV stage and follicle quality and was more often observed to be abnormal or absent in case of GV3 oocytes included in atretic follicles. Oocyte nuclear modifications therefore appear to be a prerequisite to resumption of meiosis.
\end{abstract}

Macaca fascicularis - oocyte - germinal vesicle - nuclear changes

Résumé - Etude in vivo des modifications nucléaires de l'ovocyte de Macaca fascicularis en relation avec la qualité et la taille des follicules. L'examen histologique d'ovaires de macaques Macaca fasicularis prélevés en milieu de phase folliculaire montre que les vésicules germinales des ovocytes contenus dans les follicules de diamètre $>1 \mathrm{~mm}$ peuvent présenter différentes configurations. Nous décrivons trois types d'organisation nucléaire que nous avons appelés GV1 (chromatine dispersée et en filaments), GV2 (chromatine en filaments et compacte) et GV3 (chromatine condensée autour du nucléole). La stimulation gonadotrope et l'atrésie folliculaire induisent des modifications du noyau. Ces modifications sont très importantes dans le cas de latrésie qui peut même induire la rupture de la vésicule germinale (GVBD). Nos résultats sont les suivants :

- La fréquence des ovocytes en GV1 est toujours faible mais reste plus importante pour les follicules sains comparés aux atrétiques $(22,0 \% / 4,1 \%, \mathrm{P}<0,001)$ tandis que les ovocytes en GV3 sont plus fréquents dans les follicules atrétiques comparés aux sains $(65,8 \% / 44,1 \% ; \mathrm{P}<0,001)$. 
- Les ovocytes qui reprennent la méïose in vitro sont très certainement ceux qui étaient au stade GV3 au moment de la mise en culture.

- Ces changements sont corrélés à la taille et à la qualité du follicule mais pas à la taille de l'ovocyte. La taille folliculaire moyenne augmente lorsque l'on passe du stade GV1 au stade GV3 $(P<$ $0,001)$ et ce, quelle que soit la qualité du follicule.

- Le noyau est le plus souvent observé en position périphérique même pour les ovocytes en GV1.

- L'apparence morphologique de la zone pellucide est corrélée aux différents stades nucléaires et à la qualité du follicule : c'est dans les follicules atrétiques contenant des ovocytes en GV3 qu'elle est le plus souvent observée anormale ou absente. Des modifications nucléaires de l'ovocytes semblent être un préalable indispensable à la reprise de la méiose.

Macaca fascicularis - ovocyte - vesicule germinale - modifications du noyau

\section{INTRODUCTION}

In mammals, meiosis is initiated in oocytes during fetal development but is arrested in late prophase (dictyate stage), generally before birth. At this time the oocyte contains a large nucleus, the germinal vesicle. It is generally accepted that resumption of the arrested first meiotic division (germinal vesicle breakdown : GVBD) results from the LH surge during each ovarian cycle. GVBD has also been noted in atretic ovarian follicles (Thibault, 1974; Gougeon \& Testart, 1986). It has been observed that human (Lefèvre et al., 1987; McNatty et al., 1979) and Macaca fascicularis (Lefèvre et al., 1988) oocytes recovered from atretic follicles resume meiosis in vitro at higher rates than oocytes recovered from healthy follicles (very low rate in these species). Some authors have related the changes occuring in germinal vesicles either to follicular size or stage of cycle, or both (Thibault \& Gérard, 1971; Sanyal et al., 1976; Daguet, 1980; Tesarik et al., 1983; Gougeon \& Testart, 1986). Chromatin modifications have been described which could be a prerequisite either to the occurrence of methaphase I stage or the oocyte atresia. In this study, we have observed similar changes in germinal vesicles of oocytes recovered from gonadotrophin treated Macaca fascicularis. We relate these changes to zona pellucida morphology and to follicular size and quality, at mid-follicular phase.

\section{MATERIALS AND METHODS}

\section{Animals and sampling}

Eight Cynomolgus monkeys (Macaca fascicularis), born in captivity, with regular menstrual cycles were selected for study. Their mean age $( \pm$ SEM) was 5 yr \pm 9 months. Housing, feeding and general husbandry practices have been described previously (Dang, 1977). Four females were treated with daily intramuscular injections of $25 \mathrm{IU}$ of pure FSH (Metrodin, Serono, Paris, France) plus 50 IU of hMG (Neopergonal, Serono, Paris, France) in $1.0 \mathrm{ml}$ of normal saline from day $2-7$ (day 1 : menstruation; treatment 1). Four other females were treated with daily intramuscular injections of $75 \mathrm{IU}$ of pure FSH in $1.0 \mathrm{ml}$ of normal saline from day $2-5$ only in order to induce follicular atresia (treatment 2). The 8 females were castrated on day 8 and both ovaries placed in a sterile tube containing normal saline at room temperature for transport to the laboratory within $45 \mathrm{~min}$. For each female, one randomly chosen ovary was immediately fixed in Bouin's fluid for histological studies. The contralateral ovary was rapidly dissected and the oocytes recovered for in vitro oocyle maturation studies (Lefèvre et al., 1988). 


\section{Histological methods and follicle classi- fication}

The ovaries were fixed in Bouin's fluid for 3 days, serially sectioned at $10 \mu \mathrm{m}$ and stained with haematoxylin-Masson blue. The entire population of growing follicles $\geq 1000 \mu \mathrm{m}$ in diameter was analyzed. The size and quality, i.e. healthy or atretic and the oocyte nuclear stage, were evaluated. The pycnotic index was calculated as already described (Lefèvre et al., 1988). As the pycnotic index of preovulatory follicles never exceeded $0.3 \%$, follicles exhibiting a pycnotic index $<0.3 \%$ were considered as healthy, and those with a pycnotic index $>0.3 \%$ as atretic. The oocytes were classified according to the appearance of the nucleus. Dictyate oocytes exhibiting a germinal vesicle (GV) with a dispersed and filamentous chromatin were called $\mathrm{GV} 1$ (Fig. 1). Oocytes exhibiting filaments with condensed chromatin were called GV2 (Fig. 2) and those with nuclei exhibiting total perinucleolar chromatin condensation were called GV3 (Fig. 3). When germinal vesicle breakdown had already occurred, the oocytes were classified as GVBD oocytes. We also took into account : a) the position of the germinal vesicle (GV), i.e. central and subcentral ( $C$ position) or peripheral ( $P$ position); $b)$ the histological appearance of the zona pellucida, i.e. normal, abnormal, or absent.

\section{Statistical methods}

All the comparative studies between groups were carried out on pooled data using the $\mathrm{Chi}^{2}$ test or the Student's $t$-test.

\section{RESULTS}

\section{Follicle quality related to female treat- ments}

The percentage of healthy follicles was significantly higher after treatment 1 than treatment $2(90.7 \%$ vs $18.1 \%, P<0.001$; Table I). As expected, treatment 2 induced a very high rate of atresia $(81.9 \%)$. The mean diameter of healthy follicles was significantly higher with treatment 1 compared to treatment $2(2422 \pm 92 \mu \mathrm{m}$ vs $1482 \pm 97$ $\mu \mathrm{m}, P<0,001)$.

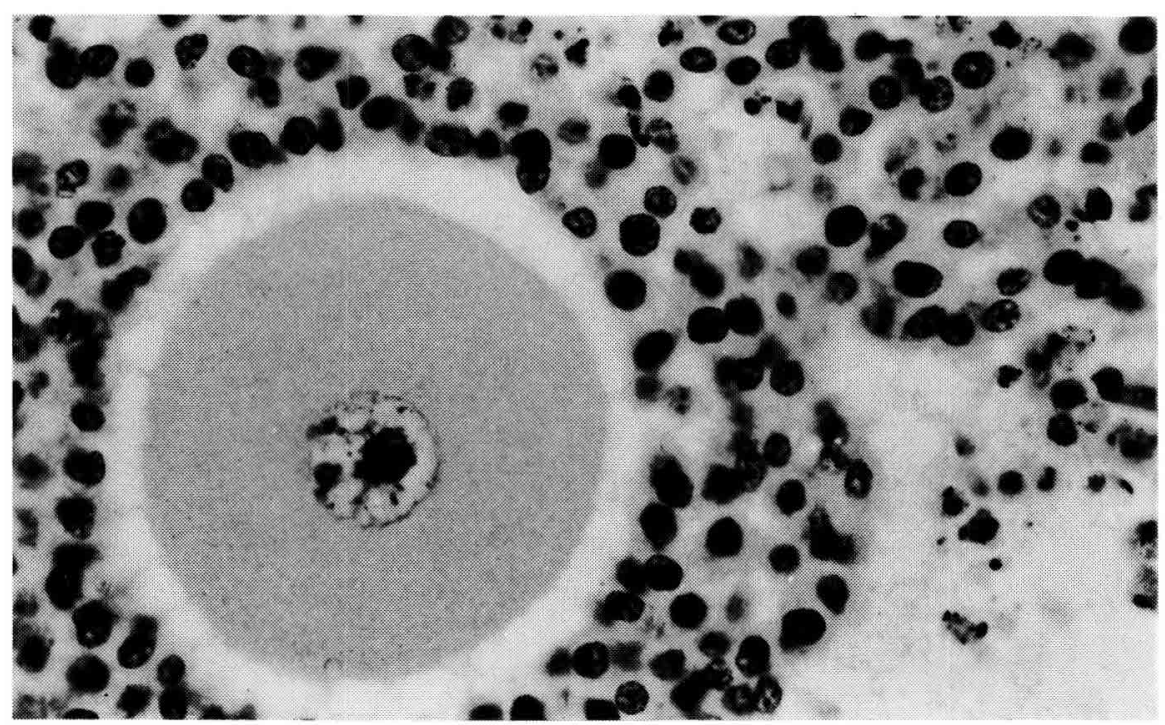

Fig. 1. GV1 : dispersed and filamentous chromatin. 


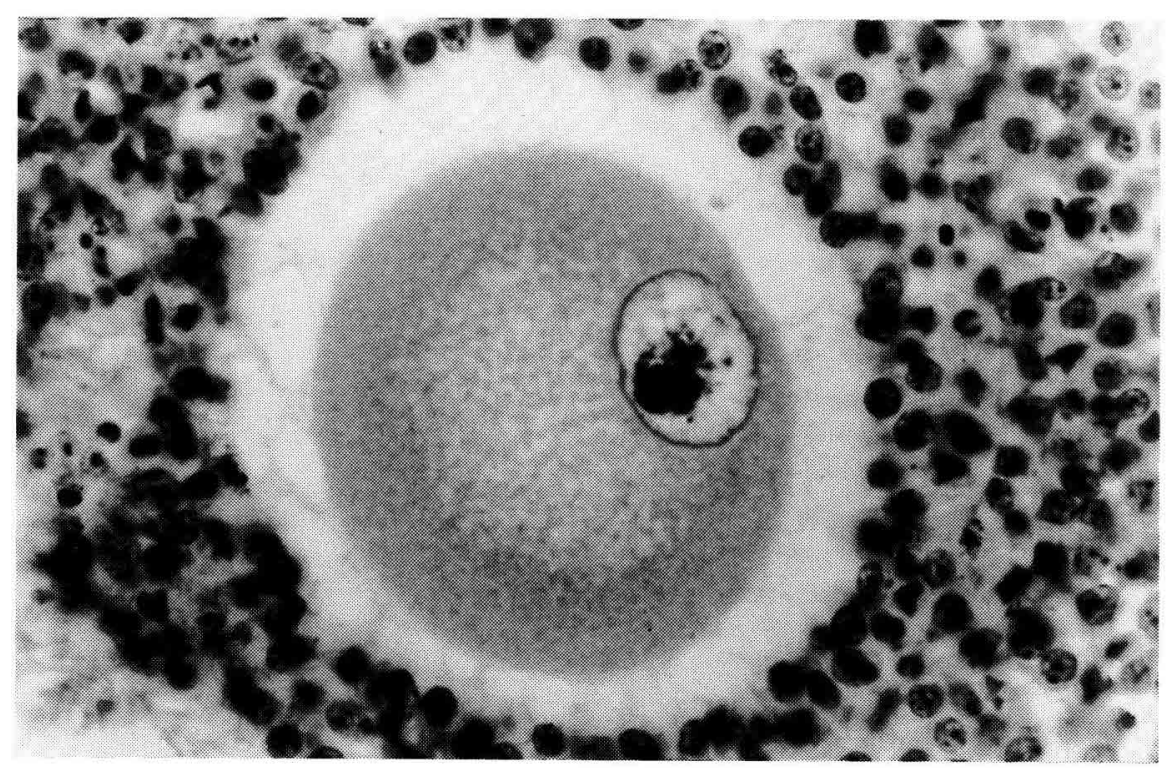

Fig. 2. GV2 : clumped and filamentous chromatin.

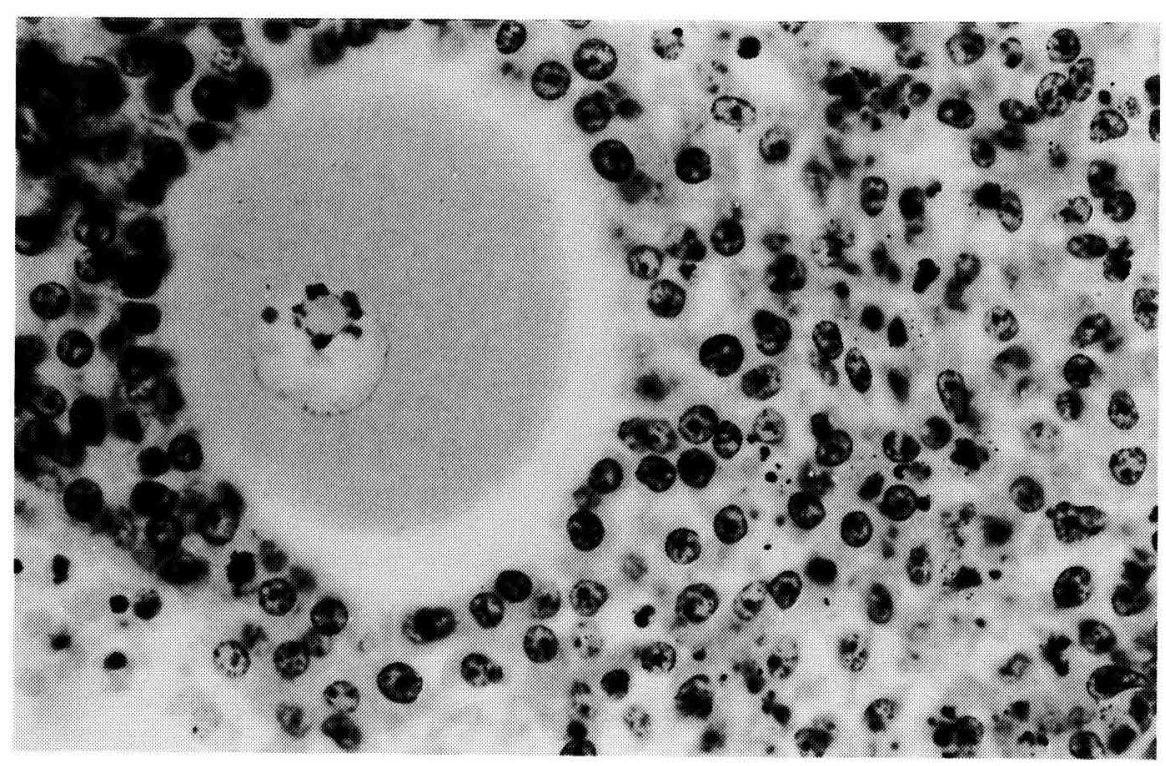

Fig. 3. GV3 : perinucleolar chromatin condensation. 
Table I. Follicular quality and size $(\mu \mathrm{m})$ at Day 8 according to the female stimulation treatments.

\begin{tabular}{lrrrrrr}
\hline $\begin{array}{l}\text { Days of } \\
\text { gonadotrophin } \\
\text { treatment }\end{array}$ & $\mathrm{N}$ & $\%$ & diameter \pm SEM & $\%$ & Atretic follicles \\
\hline $2-7$ & 140 & 90.7 & $2422 \pm 92$ & 9.3 & $2141 \pm 311$ \\
$2-5$ & 178 & 18.1 & $1482 \pm 97$ & 81.9 & $2509 \pm 65$ \\
\hline
\end{tabular}

$N$ : number of studied follicles

\section{Oocyte nuclear stage related to follicle quality and size}

The percentage of GV1 oocytes was higher in healthy compared to atretic follicles (22.0\% vs $4.1 \%, P<0,001$, Table II) whereas that of GV3 oocytes was lower in healthy than in atretic follicles $(44.1 \%$ vs $65.8 \%, P<0.001$, Table II). GVBD oocytes were observed only in atretic follicles (4.1\% vs $0.0 \%, P<0,05$, Table II). The mean diameter of the oocytes was not significantly different between the 3 nuclear stages studied regardless of follicle quality (Table II). The size of both healthy and atretic follicles increased from GV1 to GV3 stages (Table III).

\section{Germinal vesicle position related to nu- clear stage (Fig. 4)}

Significantly GV1 was observed more often in $C$ than $P$ position $(64.3 \%$ vs $35.7 \%$, $P<0.05)$ in oocytes of healthy follicles,

Table II. Frequency of the different germinal vesicle stages related to follicle quality.

\begin{tabular}{|c|c|c|c|c|c|}
\hline \multirow{2}{*}{$\begin{array}{l}\text { Follicle } \\
\text { quality }\end{array}$} & \multicolumn{5}{|c|}{ Germinal vesicle stages } \\
\hline & & GV1 & GV2 & GV3 & $G V B D$ \\
\hline Healthy & $\begin{array}{l}\text { oocyte No. } \\
(\%) \\
\text { oocyte diameter }\end{array}$ & $\begin{array}{c}28 \\
(22.0)^{\mathrm{a}} \\
100.9 \pm 0.9\end{array}$ & $\begin{array}{c}43 \\
(33.9) \\
99.0 \pm 1.2\end{array}$ & $\begin{array}{c}56 \\
(44.1)^{\mathrm{b}} \\
97.7 \pm 1.3\end{array}$ & $\begin{array}{c}0 \\
(0.0)^{c} \\
-\end{array}$ \\
\hline Atretic & $\begin{array}{l}\text { oocyte No. } \\
-(\%)\end{array}$ & $\begin{array}{c}6 \\
(4.1)^{\mathrm{a}}\end{array}$ & $\begin{array}{c}38 \\
(26.0)\end{array}$ & $\begin{array}{c}96 \\
(65.8)^{b}\end{array}$ & $\begin{array}{c}6 \\
(4.1)^{\mathrm{c}}\end{array}$ \\
\hline & oocyte diameter & $100.8 \pm 2.4$ & $99.1 \pm 0.9$ & $96.6 \pm 0.9$ & $87.5 \pm 5.7$ \\
\hline
\end{tabular}

GV1 : dispersed and filamentous chromatin; GV2 : clumped and filamentous chromatin; GV3 : perinucleolar chromatin condensation; GVBD : germinal vesicle breakdown; values with the same superscript letter were significantly different : a, $b, P<0.001, c P<0.05$. 
Table III. Mean follicular size ( $\mu \mathrm{m} \pm \mathrm{SEM}$ ) related to germinal vesicle stage and follicle quality.

\begin{tabular}{lcc}
\hline & \multicolumn{2}{c}{ Follicle quality } \\
\cline { 2 - 3 } GV stage & Healthy & Atretic \\
\hline GV1 & $1355 \pm 49^{\mathrm{a}}$ & $1708 \pm 166^{\mathrm{c}}$ \\
GV2 & $2062 \pm 93^{\mathrm{a}, \mathrm{b}}$ & $2151 \pm 91^{\mathrm{c}, \mathrm{d}}$ \\
GV3 & $3233 \pm 119^{\mathrm{b}}$ & $2722 \pm 82^{\mathrm{d}}$ \\
GVBD & - & $2160 \pm 401$ \\
\hline
\end{tabular}

GV1 : dispersed and filamentous chromatin; GV2 : clumped and filamentous chromatin; GV3 : perinucleolar chromatin condensation; GVDB : germinal vesicle breakdown; values with the same superscript letter were significantly different: ${ }^{a}, \mathrm{~b}, \mathrm{~d}, P<0.001 ; \mathrm{c}, P<0.02$.

whereas in oocytes of atretic follicles GV1 was observed more often in $P$ position (83.3\% vs $16.7 \%, P<0.05)$. Half of the GV2 were in $C$ position and half in $P$ position, whatever the follicle quality.

GV3 was observed more often in $P$ than in $C$ position in healthy and atretic follicles $(87.5 \%$ vs $12.5 \% ; P<0.001$ and $64.6 \%$ vs $35.4 \%, P<0.001$, respectively).

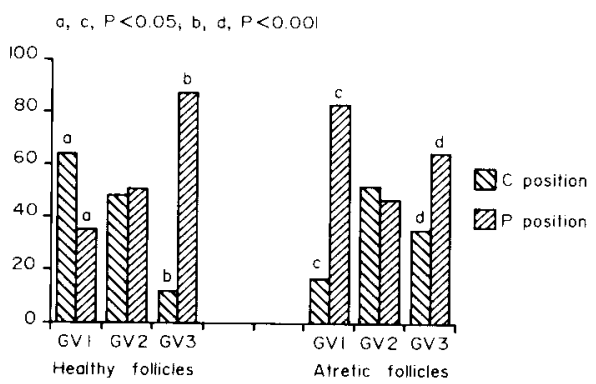

Fig. 4. Frequency of GV stages related to germinal vesicle position and to follicle quality. (C : central and subcentral position; $\mathbf{P}$ : peripheral position).

\section{Relationship between zona pellucida morphology and oocyte nuclear stages} (Fig. 5)

The frequency of normal zonae pellucidae was higher in healthy compared to atretic follicles $(74.0 \%$ vs $34.2 \%, P<0.001)$ whereas the frequency of abnormal zonae pellucidae was higher in atretic compared to healthy follicles $(46.6 \%$ vs $16.5 \%, P<$ $0.001)$. Whatever the follicle quality, the zonae pellucidae of GV1 oocytes were never absent and showed normal morphology in more than $80 \%$ of cases studied. In healthy follicles, normal zonae pellucidae

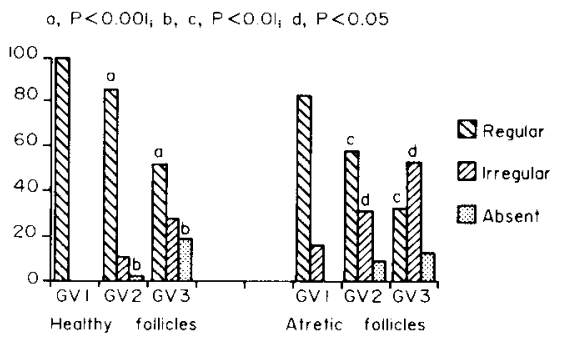

Fig. 5. Frequency of GV stages related to zona pellucida appearance and follicle quality. 
were more often observed around GV2 than GV3 oocytes $(86.0 \%$ vs $51.8 \%, \mathrm{P}<$ 0.001 ) and absence of zona pellucida occurred more in GV3 than in GV2 oocytes (19.6\% vs $2.3 \%, P<0.01)$. In atretic follicles, the percentage of normal zonae pellucidae around GV2 oocytes was higher compared to GV3 oocytes $(57.9 \%$ vs $33.3 \%, P<0.01$ ) whereas the percentage of abnormal zonae pellucidae around GV3 oocytes was higher than around GV2 oocytes $(53.1 \%$ vs $31.6 \%, P<0.05)$. GV1 oocytes never exhibited absence of zona pellucida whatever the follicle quality. The frequency of absence of zonae pellucidae around GV2 and GV3 oocytes did not differ between healthy and atretic follicles.

\section{DISCUSSION}

Our observations in gonadotrophinstimulated Macaca fascicularis confirm the existence of different chromatin configurations exhibited by the oocyte nucleus, as already observed in rat (Mandl, 1962), pig (McGaughey et al., 1979; Daguet, 1980), macaque (Thibault, 1974) and humans (Tesarik et al., 1983; Gougeon \& Testart, 1986).

In healthy follicles $\geq 1000 \mu \mathrm{m}$ in diameter, gonadotrophin stimulation induced nuclear changes in vivo. The frequency of GV3 oocytes observed at mid-follicular phase was high $(44.1 \%)$ and the nuclear changes increased with the follicular size. The largest follicles are probably more sensitive to gonadotrophin stimulation and the oocyte nuclear maturation process depends upon follicular growth. However, GV2 and GV3 oocytes have been found even in small healthy antral follicles.
Generally, at the dictyate stage the germinal vesicle is centrally located and then migrates to the periphery of the cytoplasm before meiotic resumption can occur (Hunter \& Polge, 1966; Himelstein-Braw et al., 1976; Motlik \& Fulka, 1976; Daguet, 1980; Gougeon, 1981; Thibault et al., 1987). Our results are in agreement with these observations, since we have observed a significant relationship between nuclear changes and germinal vesicle position in healthy follicles : the frequency of peripheral GV was higher in GV3 oocytes compared to GV1 $(P<0.001)$ and GV2 oocytes $(P<0.001)$. However, in a few cases GV migration occurred even in the GV1 oocyte.

In healthy follicles, the appearance of zonae pellucidae was related to GV changes. GV1 oocytes always exhibited normal zonae pellucidae but the frequencies of abnormal and absent zonae pellucidae increased with GV changes. However, at this stage in the cycle (day 8), regular zona pellucida were always observed, even at the GV3 stage ( $>50 \%$ of the oocytes were surrounded by a normal zona pellucida). Such histological modifications of the zona pellucida were probably due to biochemical and structural changes occurring with maturity which induce some fragility of the zona pellucida to histological treatments.

Our results demonstrate a significant effect of follicular atresia upon oocyte maturation process. Nuclear changes were induced at a higher frequency in atretic than in healthy follicles $(P<0.001)$. A high frequency of germinal vesicles exhibiting condensed chromatin in Macaca fascicularis atretic follicles have already been reported (Thibault, 1974). Moreover, the GVBD oocytes when observed were present only in atretic follicles. The occurrence of meiotic resumption in atretic follicles has been reported in different species (Thibault, 1974; Gougeon and Testart, 1986). Follicular 
atresia appears to facilitate GV migration toward the ooplasmic periphery (even GV1 have been observed in peripheral position) and to induce important zona pellucida modifications.

It was not possible to determine with certainty whether these nuclear changes were the prerequisite to the occurrence of MI or whether they represented the early stages of nuclear degeneration. Follicular atresia significantly reinforced the effect of gonadotrophin stimulation upon the chromatin organization inside the germinal vesicle. Perinucleolar chromatin condensation occuring in GV oocytes from healthy pig follicles has been demonstrated to be a prerequisite of meiosis resumption (Daguet, 1980). McGaughey et al. (1979) have also associated chromatin condensation with oocyte capacity to spontaneously mature in vitro.

It could be assumed that those oocytes which resume meiosis in vitro are more probably the GV3 oocytes observed in vivo. The higher frequency of GV3 oocytes observed in atretic compared to healthy follicles could be explained by our previously reported results in Cynomolgus monkey (Lefèvre et al., 1988) : oocytes recovered from atretic follicles spontaneously resume meiosis to a larger extent than those recovered from healthy follicles $(52.6 \%$ vs $30.3 \%, P<0.05)$. The GVBD rate observed in vitro is similar to the GV3 oocyte rate observed in vivo for healthy (23/76 vs $25 / 56$, not significant) and for atretic follicles (20/38 vs 63/96, not significant). We hypothesize that only the oocytes recovered at the GV3 stage are able to spontaneously mature in vitro. This would mean that the process of oocyte maturation begins inside the follicle even in the absence of an LH:hCG stimulus. The LH component in hMG used for ovarian stimulation may account for this induction.
It is important to determine the precise nuclear status of oocytes from mammals reported to resume meiosis in vitro at very high rates since such oocytes are generally recovered after stimulation of ovaries by gonadotrophin. The release of an oocyte from its inhibitory follicular environment seems insufficient to give spontaneous in vitro maturation. It may be necessary for the oocyte to have already started nuclear activation inside its follicle. However, nuclear activation is probably not systematically followed by in vivo meiotic resumption. It is probable that an other step in this process - either a release of inhibition or a stimulation - has to occur. It remains to be determined whether primate oocytes recovered from atretic follicles are able to undergo a normal maturation process, since in the ewe Moor \& Trounson (1977) have obtained embryos after in vitro fertilization of oocytes from atretic follicles.

\section{ACKNOWLEDGMENTS}

We thank the Serono Laboratories for their generous gift of human FSH and Humegon.

\section{REFERENCES}

Daguet M.C. (1980) In vivo change in the germinal vesicle of the sow oocyte during the follicular phase before the ovulatory $\mathrm{LH}$ surge. Reprod. Nutr. Develop. 20, 673-680

Dang D.C. (1977) Absence of seasonal variation in the length of the menstrual cycle and fertility of the crab-eating macaque (Macaca fascicularis) raise under natural day light ratio. Ann. Biol. Anim. Bioch. Biophys. 17, 1-7

Gougeon A.(1981) Cinétique de la croissance et de l'involution des follicules ovariens pendant le 
cycle menstruel chez la femme. Th. D2-Sci.; Univ. Pierre et Marie Curie, Paris, France

Gougeon A. \& Testart J. (1986) Germinal vesicle breakdown in oocytes of human atretic follicles during the menstrual cycle. J. Reprod. Fertil. $78,389-401$

Himelstein-Braw R., Byskov A.G., Peters H. \& Faber M.(1976) Follicular atresia in the infant human ovary. J. Reprod. Fertil. 46, 55-59

Hunter R.H.F. \& Polge C. (1966) Maturation of follicular oocytes in the pig after injection of human chorionic gonadotrophin. J. Reprod. Fertil. $12,525.531$

Lefèvre B., Gougeon A. \& Testart J.(1987) In vitro oocyte maturation : some questions concerning the initiation and prevention of this process in humans. Human Reprod. 2, 495-497

Lefèvre B., Gougeon A., Peronny H.\& Testart J. (1988) Effect of cumulus cell mass and follicle quality on in vitro maturation of cynomolgus monkey oocytes. Human Reprod. 3, 891-893

Mandl A.M.(1962) Preovulatory changes in the oocyte of the adult rat. Proc. Roy. Soc. B. 158, 105-118

McGaughey R.W., Montgomery D.H. \& Richter J.D. (1979) Germinal vesicle configurations, and patterns of polypeptide synthesis of porcine oocytes from antral follicles of different size as related to their competency for spontaneous maturation. J. Exp. Zool. 209, 239-254

McNatty K.P., Moore Smith D., Makris A., Osathanondh R. \& Ryan K.J. (1979) The micro- environment of the human antral follicle : interrelationships among the steroid levels in antral fluid, the population of granulosa cells, and the status of the oocyte in vivo and in vitro. J. Clin. Endocr. Metab. 49, 851-860

Moor R.M. \& Trounson A.O. (1977) Hormonal and follicular factors affecting maturation of sheep oocytes in vitro and their subsequent developmental capacity. J. Reprod. Fertil. 49, 101109

Motlik J. \& Fulka J. (1976) Breakdown of the germinal vesicle in pig oocytes in vivo and in vitro. J. Exp. Zool. 198, 155-162

Sanyal M.M., Taymor M.L. \& Berger M.J. (1976) Cytologic features of oocytes in the adult human ovary. Fert. Steril. 27, 501-510

Tesarik J., Travnik P., Kopečný V. \& Kristek F. (1983) Nucleolar transformations in the human oocyte after completion of growth. Gamete Res. 8, 267-277

Thibault C. (1974) Experimental approaches to normal and abnormal mammalian oocyte maturation and ageing. In : Chromosomal Errors in Relation to Reproductive Failure (A. Boue \& C. Thibault, eds.), Colloque INSERM, Paris

Thibault C., Szöllözi D. \& Gérard M. (1987) Mammalian oocyte maturation. Reprod. Nutr. Dévelop. 27, 865-896

Thibault C. \& Gérard M. (1971) Maturation et fécondation in vitro de l'ovocyte de la lapine. In : Malformations Congénitales des Mammifères (H. Tuchmann-Duplessis, ed.), Masson,Paris, pp. 13-25 